Article

\title{
Examining the Input and Output Linkages in Agricultural Production Systems
}

\author{
Dong Hee Suh ${ }^{1, *(\mathbb{D})}$ and Charles B. Moss ${ }^{2}$ (i) \\ 1 Department of Food and Resource Economics, Korea University, 145 Anam-ro, Seongbuk-gu, \\ Seoul 02841, Korea \\ 2 Food and Resource Economics Department, University of Florida, Gainesville, FL 32611-0240, USA; \\ cbmoss@ufl.edu \\ * Correspondence: dhsuh@korea.ac.kr
}

Citation: Suh, D.H.; Moss, C.B.

Examining the Input and Output Linkages in Agricultural Production Systems. Agriculture 2021, 11, 54. https://doi.org/10.3390/ agriculture11010054

Received: 9 December 2020 Accepted: 8 January 2021 Published: 11 January 2021

Publisher's Note: MDPI stays neutral with regard to jurisdictional clai$\mathrm{ms}$ in published maps and institutional affiliations.

Copyright: $\odot 2021$ by the authors. Licensee MDPI, Basel, Switzerland. This article is an open access article distributed under the terms and conditions of the Creative Commons Attribution (CC BY) license (https:// creativecommons.org/licenses/by/ $4.0 /)$.

\begin{abstract}
This paper conducts a comprehensive analysis of the agricultural sector's resource allocation and production decisions. This paper uses the differential systems with quasi-fixity to evaluate the complete agricultural production system, which examines the input and output linkages in terms of elasticities. The differential systems are estimated using the maximum likelihood estimation technique based on the two-step profit-maximizing procedure in theory. The results reveal that livestock production requires more intermediate inputs, but crop production depends on all the inputs, such as labor, capital, and intermediate inputs. In addition, the results show that input demand is inelastic, indicating that the agricultural sector has little flexibility in adjusting the demand for inputs in response to changes in input prices. Substitutable relationships among labor, capital, and intermediate inputs exist, which may reduce the pressures on production costs when input prices rise. Regarding the quasi-fixed input, land expansion changes the composition of labor and intermediate inputs, showing that the agricultural sector reduces the intensive margin when it pursues the extensive margin. Furthermore, the results show that agricultural supply is not very responsive to the respective price changes. Along with the inelastic output supply, there exist substitutable relationships between livestock and crop supply, showing that relative price changes can alter output composition in supply. The agricultural sector also reallocates more land areas into crop production rather than livestock production.
\end{abstract}

Keywords: agricultural production; differential input demand; differential output supply; crop output; farm-related output; livestock output; quasi-fixity

\section{Introduction}

According to the Food and Agriculture Organization (FAO), the food price index increased by about 121\%, from 91.1 in 2000 to 171.6 in 2018, hitting 229.9 in 2011. Specifically, the cereal price index increased from 85.8 in 2000 to 193.1 in 2018, while the meat price index increased from 96.5 in 2000 to 169.3 in 2018. The surge in food prices has raised concerns about the issues of food security and hunger because high food prices negatively affect low-income consumers in developing and developed countries. The increased food prices could threaten food security, thereby reducing food accessibility and could increase hunger, causing inadequate nutritional outcomes [1-10]. Given that a rise in agricultural commodity prices translates into an increase in food prices, the current high food prices are attributable to a combination of shocks to the supply and demand systems in the agricultural sector. While rising production costs and slowing growth in agricultural production have put pressures on agricultural commodity prices, growing demand for agricultural commodities and biofuels have reinforced high price levels [11-15].

The agricultural sector in the United States (US) has experienced similar supply and demand shocks, and it has faced several challenges that require an adjustment in agricultural input demand. While the annual growth rate of the total factor productivity 
was about $1.42 \%$ between 1948 and 2011, the annual growth rates of agricultural output and total input use were about $1.49 \%$ and $0.07 \%$, respectively [16]. When it comes to agricultural input usage, the growth of total input use has remained almost unchanged, but the composition of inputs used for production has changed over the period. The use of labor has been replaced either by machinery and agricultural chemicals, such as fertilizers and pesticides or by purchased contract labor services [16,17]. In addition, rising energy prices have forced the sector to endure increasing energy costs under the producers' budget constraints [18], and the agricultural sector has substituted chemicals for land to intensify productivity as land becomes scarce relative to other inputs $[19,20]$. The composition changes in input usage were attributed to rising and volatile input prices and unproductive weather conditions, which seemed to put pressure on production costs.

Moreover, along with the input changes, the US agricultural sector has facilitated an adjustment in agricultural output supply. In the crop sector, there have been pressures to meet the increased demand for agricultural commodities in developing countries and shifts from food and feed crops to fuel crops to meet the increased demand for biofuels (e.g., ethanol). The increased demand for agricultural commodities pushed the crop sector to expand production capacity, and the increased demand for biofuel feedstocks motivated the adjustment in the composition of crops produced [21]. In particular, the increased biofuel production increased the competition for land and other resources between biofuel and non-biofuel crops. Due to the favorable prices of biofuel crops, crop producers have allocated more resources to biofuel crops or replaced non-biofuel crops with biofuel crops. The increased demand for corn induced higher corn prices, and in turn, motivated crop producers to plant corn on fields used originally for other crops [19,20,22,23].

In addition to the adjustment in the crop sector, the livestock sector has responded to rising feed prices and varying livestock prices. The adjustment in the livestock sector was more complicated because it reflected the price transmission from feed crops. While there has been a growing demand for livestock products themselves, rising crop prices for livestock feed has induced the livestock sector to adjust its composition of livestock produced [24]. The biofuel policies (e.g., ethanol subsidy and mandate) stimulated corn demand and supply, and a surge in corn prices driven by the increased corn demand was translated eventually into an increase in the feed cost of livestock production $[24,25]$. That is, due to the competition for corn between livestock and ethanol producers, insufficient corn supply to the feed market induced high corn prices, and in turn, made livestock producers adjust their input demand and output supply [24]. The adjustment in the agricultural production system was inevitable because the system had to respond to varying market circumstances and policies. The external factors seemed to influence the complete production system, which could strengthen the linkages between the crop and livestock sectors.

Despite the potential for such linkages, most policy measures have focused only on a sector without considering its impact on the other sector. A policy ignoring the potential sectoral effects may be problematic because it can create unintended consequences in related sectors. For instance, if a policy measure affects the crop (livestock) sector without understanding the complete agricultural production system, it may reduce the livestock (crop) supply, causing high and volatile livestock (crop) prices. Such linkages may require policymakers to consider the overall effects of a policy measure to attain a stable supply of all agricultural crop and livestock products. However, past studies have not focused on the sectoral linkages in agricultural supply. The literature was limited to examining a part of production systems without considering inherent relationships among inputs and outputs, and it was also dependent mainly on the optimization and simulation methods to examine the production system's functioning and response capability [26-29].

Thus, this paper examines how the US agricultural sector allocates resources and makes production decisions, employing the differential approach to the agricultural production system with a quasi-fixed input. We first model the complete production system and suggest an estimation strategy to assess the responsiveness of input demand and 
output supply to the relative prices. The findings can contribute to understanding how the agricultural production system responds to varying economic circumstances. Moreover, this paper identifies the relationships among primary inputs and outputs. Specifically, we evaluate the relationships among labor, capital, and intermediate inputs and identify the relationships among livestock, farm-related, and crop outputs. The findings can help policymakers understand what factors must be considered in policy measures related to the crop, farm-related, and livestock sectors. Finally, we consider the response of input demand and output supply to a change in land areas. The findings offer implications about the intensive and extensive margin in producers' decisions by evaluating how the agricultural sector allocates inputs and outputs due to a change in agricultural land.

\section{Materials and Methods}

The differential production systems with quasi-fixity were employed to explore the agricultural sector's input and output decisions. As a theory-based econometric model is more accurate than a statistics-based model [30], the differential systems were applied empirically to examine economic decisions about input demand and output supply $[22,24,31-40]$. While the differential systems with quasi-fixity included input demand and output supply equations derived theoretically, the estimation of the differential input demand and output supply systems showed a comprehensive short-runlong-run behavior of the multiproduct firm. Moreover, the differential approach is beneficial for providing a complete picture of the production system related to resource allocation and production decisions in terms of elasticities. While the differential systems have been used for several empirical research, this section briefly describes the differential systems with quasi-fixity following Livanis and Moss [38] and suggests an efficient strategy to estimate both input demand and output supply systems.

Consider a multiproduct firm that produces $m$ outputs, $q=\left(q_{1}, \cdots, q_{m}\right)^{\prime}$ using $n$ variable inputs, $x=\left(x_{1}, \cdots, x_{n}\right)^{\prime}$ and a quasi-fixed input, $z$. The differential input demand system is derived from cost minimization. That is, the multiproduct firm is assumed to optimize its input combination through minimizing its variable production cost $(V C)$,

$$
\min V C=w^{\prime} x
$$

where $w=\left(w_{1}, \cdots, w_{n}\right)^{\prime}$ is the input price vector. When we express $f(x, q, z)=0$ as the production function in the natural logarithmic form, the multiproduct firm's optimal variable inputs are chosen from cost minimization subject to the implicit form of the production function [38]. When the differential is represented by a finite change in each variable (i.e., symbol $\Delta$ ), the $i$ th differential input demand equation of the multiproduct firm at time $t$ is written

$$
\bar{\delta}_{i t} \Delta \ln x_{i t}=\bar{\gamma}_{y t} \sum_{r=1}^{m} \theta_{i}^{r} \bar{h}_{r t} \Delta \ln q_{r t}+\sum_{j=1}^{n} \pi_{i j} \Delta \ln w_{j t}+\bar{\gamma}_{z t} \delta_{i} \Delta \ln z_{t}
$$

where $\bar{g}_{r t}=\left(g_{i t}+g_{i t-1}\right) / 2$ is the $i$ th input's average cost share, and $\bar{h}_{r t}=\left(h_{r t}+h_{r t-1}\right) / 2$ is the $r$ th output's average revenue share. Considering the linkage between revenue and cost, Equation (1) includes the average revenue-cost ratio, $\bar{\gamma}_{y t}=\sqrt{R_{t} R_{t-1} / C_{t} C_{t-1}}$ where the revenue is $R=p^{\prime} q$ given $p=\left(p_{1}, \cdots, p_{m}\right)^{\prime}$ is the output price vector. In addition, when the quasi-fixed input's price is $v$, Equation (1) includes the average ratio of quasi-fixed cost to variable cost, $\bar{\gamma}_{z t}=\sqrt{F C_{t} F C_{t-1} / V C_{t} V C_{t-1}}$, where the quasi-fixed cost is $F C=v z$. While the input demand equations are expressed in terms of output levels, input prices, and a quasi-fixed input, parameters, $\theta_{i}^{r}, \pi_{i j}$, and $\delta_{i}$ represent the response of the input demand to output quantities, input prices, and quasi-fixed inputs, respectively.

On the other hand, the differential output supply system is derived from profit maximization. The multiproduct firm's optimal outputs are chosen to maximize its profit $(\pi)$,

$$
\max \pi=R-V C
$$


where $R$ and $V C$ are total revenue and variable cost. Given the production function, $f(x, q, z)=0$, the profit maximization yields the $r$ th differential output supply equation of the multiproduct firm at time $t$ as

$$
\bar{\gamma}_{t} \bar{h}_{r t} \Delta \ln q_{r t}=\sum_{s=1}^{m} \psi_{r s}\left(\Delta \ln p_{s t}-\sum_{i=1}^{n} \theta_{i}^{s} \Delta \ln w_{i t}\right)+\mu_{r} \Delta \ln z_{t}
$$

where $\psi_{r s}$ are parameters representing the response of the output supply to output and input prices, and $\mu_{r}$ are the response of the output supply to quasi-fixed inputs. Due to parameter $\theta_{i}^{S}$ in both Equations (1) and (2), the differential systems reflect the interaction between input and output systems.

The differential input demand and output supply systems specified in Equations (1) and (2) are estimated using the maximum likelihood technique with the bootstrapping method [41-43]. While a variety of parameters is estimated at once, we use a two-step estimation procedure to alleviate the problem of convergence due to the parameters $\theta_{i}^{r}$ in both input demand and output supply systems [22,24]. This procedure is based on the two-step profit maximization, in theory, assuming that the multiproduct firm first chooses the cost-minimizing input levels and then choose the profit-maximizing output levels [44]. Considering the complexity of the systems, this two-step procedure estimates the parameters efficiently.

In the first step, the input demand system was estimated with homogeneity and symmetry imposed. Adding the error term $\left(\varepsilon_{i t}\right)$ normally distributed to Equation (1), we estimated $\theta_{i}^{r}$ and $\pi_{i j}$ with the theoretical restrictions, such as adding-up $\left(\sum_{i=1}^{n} \theta_{i}^{r}=1\right)$, homogeneity $\left(\sum_{j=1}^{n} \pi_{i j}=0\right)$, and symmetry $\left(\pi_{i j}=\pi_{j i}\right)$. The bootstrapping procedure was also used to ensure that the input demand system was concave $[45,46]$. Once the parameters were estimated, the estimates were then used to calculate the elasticities of input demand with respect to outputs, input prices, and quasi-fixed inputs. Dividing both sides of Equation (1) by $\bar{g}_{i t}$ yields

$$
\eta_{i r}=\frac{\bar{\gamma}_{t} \theta_{i}^{r} \bar{h}_{r t}}{\bar{g}_{i t}}
$$

which is the elasticity of input $i$ 's demand with respect to output $r$. The output elasticity of input demand measures the percentage changes in input demand with respect to a one percent change in output levels. It also yields

$$
\xi_{i j}=\frac{\pi_{i j}}{\bar{g}_{i t}}
$$

which indicates the elasticity of input $i$ 's demand with respect to input $j$ 's price. The price elasticity of input demand measures the percentage changes in input demand with respect to a one percent change in input prices. Moreover, the elasticity of input $i$ 's demand with respect to the quasi-fixed input. The quasi-fixed input elasticity of input demand is

$$
\tau_{i}=\frac{\bar{\gamma}_{z z} \delta_{i}}{\bar{g}_{i t}}
$$

which measures the percentage changes in input demand with respect to a one percent change in the level of the quasi-fixed input.

In the second step, the estimates of $\theta_{i}^{r}$ obtained in the first step were substituted into the output supply systems. The output supply system was then estimated with the error term $\left(\varepsilon_{r t}\right)$ normally distributed to Equation (2). With homogeneity $\left(\sum_{s=1}^{m} \psi_{r s}=0\right)$ and symmetry $\left(\psi_{r s}=\psi_{s r}\right)$ imposed, the bootstrapping method also tested for convexity [45,46]. The estimates obeying the theoretical conditions were used to calculate the elasticities of 
output supply with respect to output prices and quasi-fixed inputs. Dividing both sides of Equation (2) by $\bar{\gamma}_{t} \bar{h}_{r t}$ yields

$$
\omega_{r s}=\frac{\psi_{r s}}{\bar{\gamma}_{t} \bar{h}_{r t}}
$$

which represents the elasticity of the $r$ th output supply with respect to the sth output price. The price elasticity of output supply measures the percentage changes in output supply with respect to a one percent change in output prices. In addition, the elasticity of the $r$ th output supply with respect to the quasi-fixed input is

$$
\varphi_{r s}=\frac{\mu_{r}}{\bar{\gamma}_{t} \bar{h}_{r t}}
$$

which measures the percentage changes in output supply with respect to a one percent change in the level of the quasi-fixed input.

\section{Empirical Findings}

\subsection{Data}

For our empirical analysis, we obtained data from the Agricultural Productivity published by the Economic Research Service of the United States Department of Agriculture (USDA-ERS, Washington DC, USA), which provides a statistical database for US agricultural production (Table 1). The data used in this analysis included annual quantities and prices from 1948 to 2011. The selected primary inputs were labor, capital, intermediate inputs, and land. According to the USDA-ERS, labor includes hired and self-employed labor, and capital includes inventories, such as non-durable items and durable assets. In addition, intermediate inputs cover feed and seed, energy, fertilizer and lime, pesticides, purchased services, and other intermediate goods, and land includes owned and rented land. Figure 1 presents the prices and quantities of inputs used for agricultural production. While the input prices increased over the period between 1948 and 2011, the share of labor decreased from $67 \%$ to $22 \%$, and the share of capital slightly increased from $0.03 \%$ to $0.9 \%$. The share of intermediate inputs increased dramatically from $19 \%$ to $62 \%$ over the same period, and that of land slightly increased from $13.7 \%$ to $15.1 \%$.

Table 1. Descriptive Statistics of Variables.

\begin{tabular}{ccccc}
\hline Variables & Mean & Std. Dev. & Min. & Max. \\
\hline Input Variables & & & & \\
Labor Price & 0.37 & 0.35 & 0.041 & 1.22 \\
Labor Quantity & 112.91 & 53.28 & 53.68 & 248.53 \\
Capital Price & 1.04 & 0.82 & 0.06 & 2.42 \\
Capital Quantity & 1.94 & 0.30 & 1.26 & 2.34 \\
Intermediates Price & 0.60 & 0.35 & 0.22 & 1.54 \\
Intermediates Quantity & 122.22 & 26.54 & 68.90 & 164.56 \\
Land Price & 0.55 & 0.44 & 0.13 & 2.56 \\
Land Quantity & 43.14 & 4.49 & 37.26 & 51.00 \\
Output Variables & & & & \\
Livestock Output Price & 0.60 & 0.28 & 0.25 & 1.25 \\
Livestock Output Quantity & 96.07 & 21.75 & 57.31 & 131.57 \\
Farm-Related Output Price & 0.64 & 0.38 & 0.18 & 1.54 \\
Farm-Related Output Quantity & 7.37 & 4.54 & 2.53 & 15.94 \\
Crop Output Price & 0.78 & 0.33 & 0.36 & 1.74 \\
Crop Output Quantity & 91.38 & 30.95 & 46.81 & 141.27 \\
\hline
\end{tabular}

Note: Price index was measured relative to $2005=1$, and quantity was measured in billions; Source: Agricultural Productivity in the United States, USDA-ERS. 

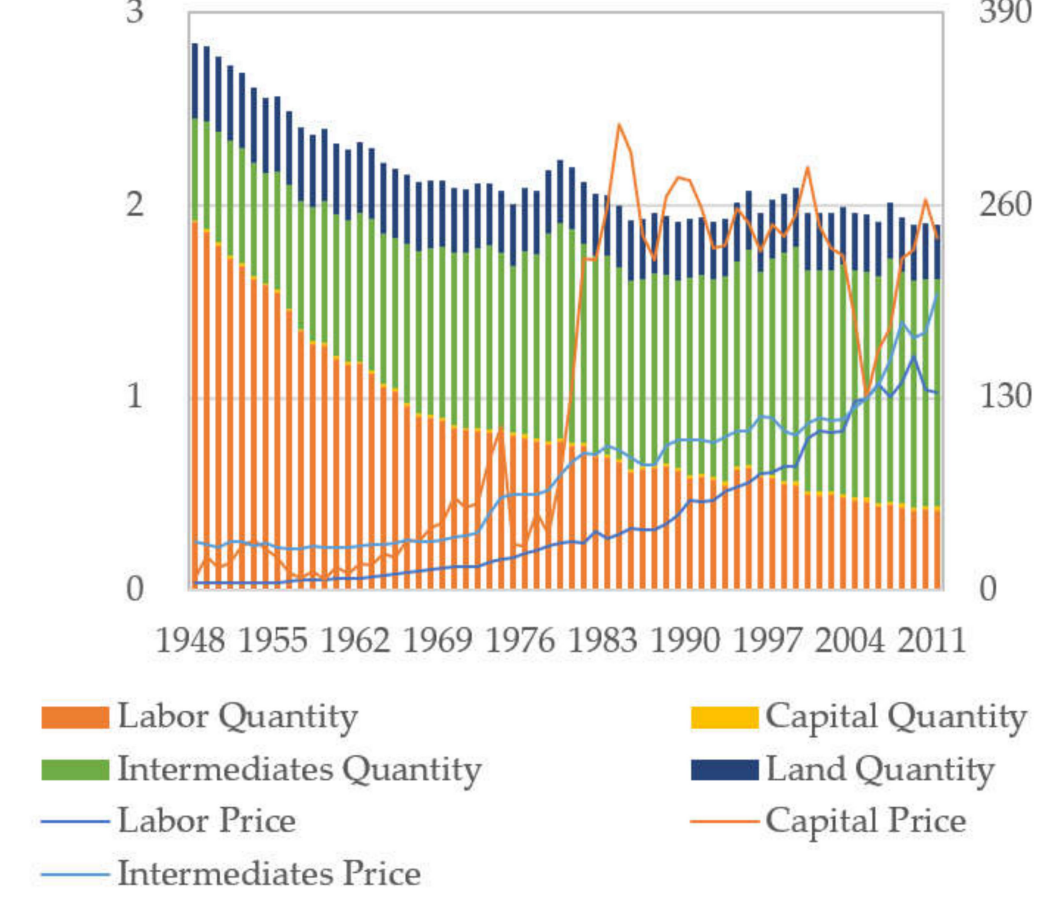

Figure 1. Inputs used by the US Agricultural Sector; Note: Price indices are relative to $2015=1$, and quantities are measured in billions. Source: Agricultural Productivity in the United States, USDA-ERS.

For the major types of agricultural outputs, three outputs were considered: livestock, farm-related, and crop outputs. The data for livestock output included meat animals, dairy, poultry, and eggs, and miscellaneous livestock outputs not separately identified, while the data for farm-related output represented goods and services from certain non-agricultural or secondary activities, which were closely related to agricultural production. The data for crop output included food grains, feed grains, oil crops, vegetables and melons, fruits and nuts, sugar crops, maple, seed crops, miscellaneous field crops, hops, mint, greenhouse and nursery, and mushrooms. The prices and quantities of outputs supplied by the agricultural sector are described in Figure 2. While all the output prices increased over the period, the shares of crop and farm-related outputs increased from $46 \%$ and $2 \%$ in 1948 to $48 \%$ and $5 \%$ in 2011, respectively, but the share of livestock output decreased from $51 \%$ to $47 \%$ over the period. Given the data, the US agricultural sector is now assumed to be a multiproduct firm that produces three major outputs using four primary inputs. 
2

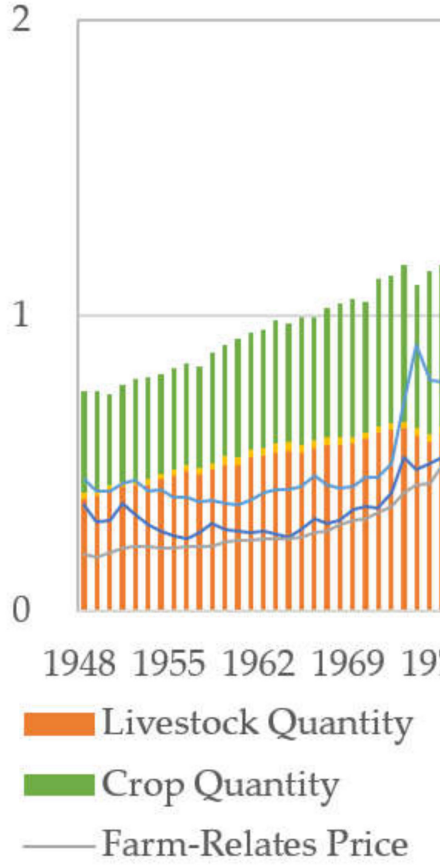

300

150

Figure 2. Outputs supplied by the US Agricultural Sector; Note: Price indices are relative to $2015=1$, and quantities are measured in billions. Source: Agricultural Productivity in the United States, USDA-ERS.

\subsection{Estimation Results}

Table 2 presents the estimation results of the differential systems with quasi-fixity. The differential input demand system was estimated by dropping the equation for intermediate inputs, while the differential output supply system was estimated by dropping the equation for crop outputs. Since the estimates themselves have no direct meaning, we calculated the elasticities based on Equation (3) through Equation (7). Table 3 reveals the output elasticities of input demand obtained from the estimates of the differential input demand system. Statistical evidence shows that input demand is inelastic with respect to output changes because the absolute values of all the estimates are less than unity. Specifically, a $1 \%$ increase in livestock outputs raises the demand for intermediate inputs $(0.85 \%)$. The results show that livestock production is more likely to depend on feed, energy, and other intermediate goods rather than the other inputs. In addition, more farm-related outputs require more capital $(0.13 \%)$ and intermediate inputs $(0.04 \%)$, which is attributed to farmrelated goods and services produced by certain non-agricultural or secondary activities. On the other hand, the results show that crop production depends on the use of all the inputs, increasing the demand for labor $(0.73 \%)$, capital $(0.85 \%)$, and intermediate $(0.72 \%)$ inputs. While increasing all agricultural outputs is accompanied by an increase in the demand for intermediate inputs, an increase in crop outputs requires more labor, capital, and intermediate inputs. 
Table 2. Estimation Results.

\begin{tabular}{cccc}
\hline Parameters & Estimates & Parameters & Estimates \\
\hline$\theta_{1}^{1}$ & -0.011 & $\pi_{23}$ & $0.000^{*}$ \\
$\theta_{2}^{1}$ & $(0.083)$ & & $(0.000)$ \\
$\theta_{1}^{2}$ & 0.004 & $\delta_{1}$ & $2.340^{* * *}$ \\
$\theta_{2}^{2}$ & $(0.011)$ & & $(0.650)$ \\
$\theta_{1}^{3}$ & 0.256 & $\delta_{2}$ & -0.022 \\
$\theta_{2}^{3}$ & $(0.177)$ & & $(0.084)$ \\
& $0.051^{* *}$ & $\psi_{11}$ & $0.016^{*}$ \\
$\pi_{11}$ & $(0.025)$ & & $(0.010)$ \\
& $0.271^{* * *}$ & $\psi_{12}$ & 0.005 \\
$\pi_{12}$ & $(0.023)$ & & $(0.006)$ \\
& $0.020^{* * *}$ & $\psi_{23}$ & 0.009 \\
& $(0.002)$ & $\mu_{1}$ & $(0.007)$ \\
& $-0.067^{* * *}$ & & $-0.694 * *$ \\
& $(0.014)$ & $\mu_{2}$ & $-0.197)$ \\
& $0.003^{* *}$ & & $(0.101$ \\
\end{tabular}

Note: Bootstrap standard errors are in parentheses; ${ }^{* * *}$ Denotes statistical significance at the $1 \%$ level; ${ }^{* *}$ Denotes statistical significance at the $5 \%$ level; ${ }^{*}$ Denotes statistical significance at the $10 \%$ level.

Table 3. Output Elasticities of Input Demand.

\begin{tabular}{cccc}
\hline \multirow{2}{*}{ Elasticity of } & \multicolumn{3}{c}{ With Respect to } \\
\cline { 2 - 4 } & Livestock Output & Farm-Related Output & Crop Output \\
\hline \multirow{2}{*}{ Labor Demand } & -0.024 & 0.042 & $0.731^{* * *}$ \\
& $(0.186)$ & $(0.029)$ & $(0.062)$ \\
Capital Demand & 0.148 & $0.131^{* *}$ & $0.846^{* * *}$ \\
Intermediates & $(0.370)$ & $(0.064)$ & $(0.103)$ \\
Demand & $0.850^{* * *}$ & $0.043^{* * *}$ & $0.718^{* * *}$ \\
& $(0.070)$ & $(0.011)$ & $(0.024)$
\end{tabular}

Note: Bootstrap standard errors are in parentheses; ${ }^{* * *}$ Denotes statistical significance at the $1 \%$ level; ${ }^{* *}$ Denotes statistical significance at the $5 \%$ level.

Table 4 shows the estimation results of the differential input demand system in terms of the price and quasi-fixed input elasticities of input demand. The own-price elasticities presented in diagonal elements of the second column through the fourth column are all negative, showing that input demand is very inelastic with respect to the price change. The results show that the demand for labor $(-0.25 \%)$, capital $(-0.02 \%)$, and intermediate $(-0.09 \%)$ inputs responded little to changes in their own prices. This means that the agricultural sector is not very responsive to changes in input prices, although it has changed the composition of inputs used for production over the past decades. In Table 4, the cross-price elasticities are shown in off-diagonal elements. The positive estimates showed a substitutable relationship among labor, capital, and intermediate inputs. That is, a $1 \%$ increase in the price of labor led to approximately a $0.16 \%$ increase in the demand for capital, while the increased capital price caused about a $0.10 \%$ increase in the demand for labor. Moreover, the increased labor price induced a $0.09 \%$ increase in the demand for intermediate inputs, while the increased price of intermediate inputs raised the demand for labor by $0.24 \%$. Statistical evidence revealed that labor was not a perfect substitute for capital and intermediate inputs, or vice versa. The agricultural sector adjusts input composition in response to changes in the relative prices of inputs. Regarding the response of input demand to land expansion, it was likely to increase the demand for labor $(1.98 \%)$ but decrease the demand for intermediate inputs. The results were related to agricultural producers' decisions about the intensive and extensive margins: intensive margin through an increase in productivity or extensive margin through an increase in agricultural land [47]. When the agricultural sector pursues the extensive 
margin increasing land areas for production, the results imply that it increased the demand for labor proportionally but reduced intermediate inputs related to the intensive margin increasing productivity.

Table 4. Price and Quasi-Fixed Input Elasticities of Input Demand.

\begin{tabular}{ccccc}
\hline \multirow{2}{*}{ Elasticity of } & \multicolumn{4}{c}{ With Respect to } \\
\cline { 2 - 5 } & Labor Price & Capital Price & Intermediates Price & Land \\
\hline \multirow{2}{*}{ Labor Demand } & $-0.250^{* * *}$ & $0.010^{* *}$ & $0.239^{* * *}$ & $1.971^{* * *}$ \\
& $(0.052)$ & $(0.005)$ & $(0.052)$ & $(0.547)$ \\
Capital Demand & $0.163^{* *}$ & $-0.020^{*}$ & $-0.143^{*}$ & -0.295 \\
& $(0.079)$ & $(0.011)$ & $(0.075)$ & $(1.101)$ \\
Intermediates Demand & $0.090^{* * *}$ & $-0.003^{*}$ & $-0.087^{* * *}$ & $-0.418^{* *}$ \\
& $(0.019)$ & $(0.002)$ & $(0.019)$ & $(0.212)$ \\
\hline
\end{tabular}

Note: Bootstrap standard errors are in parentheses; ${ }^{* * *}$ Denotes statistical significance at the $1 \%$ level; ${ }^{* *}$ Denotes statistical significance at the $5 \%$ level; ${ }^{*}$ Denotes statistical significance at the $10 \%$ level.

The response of output supply to prices and land areas is presented in Table 5, in terms of the price and quasi-fixed input elasticities of output supply. When it comes to the positive own-price elasticities in diagonal elements of the second column through the fourth column, statistical evidence revealed that the supply of agricultural outputs was very inelastic with respect to the price change. The supply of crop and livestock outputs was responsive to their prices, but the extent to which the own-prices raise the supply of crop $(0.05 \%)$ and livestock $(0.03 \%)$ outputs was very small. On the other hand, the estimated cross-price elasticities in off-diagonal elements reflected the output relationship between crop and livestock outputs. Statistical evidence showed that the agricultural sector substituted the crop output for the livestock output or vice versa; negative estimates revealed the substitutable relationship in supply. That is, a $1 \%$ increase in the price of livestock output reduced the crop supply by $0.03 \%$, while an increase in the price of crop output reduced the livestock supply by $0.03 \%$. Despite the small magnitudes, the agricultural sector adjusted output composition in response to the changes in the relative prices of crop outputs to livestock outputs. Moreover, land expansion led to the adjustment in output supply because a $1 \%$ increase in land areas reduced livestock supply by $1.15 \%$ but increased crop supply by $2.48 \%$. The agricultural sector was more likely to reallocate the expanded land areas to increase crop outputs output rather than livestock outputs.

Table 5. Price and Quasi-Fixed Input Elasticities of Output Supply.

\begin{tabular}{ccccc}
\hline \multirow{2}{*}{ Elasticity of } & \multicolumn{4}{c}{ With Respect to } \\
\cline { 2 - 5 } & Livestock Price & Farm-Relates Price & Crop Price & Land \\
\hline \multirow{2}{*}{ Livestock Supply } & $0.027^{*}$ & 0.008 & $-0.034^{*}$ & $-1.151^{* * *}$ \\
& $(0.016)$ & $(0.009)$ & $(0.020)$ & $(0.326)$ \\
Farm-Relates Supply & 0.104 & 0.213 & -0.316 & -2.286 \\
& $(0.126)$ & $(0.149)$ & $(0.240)$ & $(2.343)$ \\
Crop Supply & $-0.029^{*}$ & -0.019 & $0.048^{*}$ & $2.479 * * *$ \\
& $(0.017)$ & $(0.015)$ & $(0.027)$ & $(0.330)$ \\
\hline
\end{tabular}

Note: Bootstrap standard errors are in parentheses; ${ }^{* * *}$ Denotes statistical significance at the $1 \%$ level; * Denotes statistical significance at the $10 \%$ level.

\section{Discussion}

While the US agricultural sector is overcoming the challenges from rising production costs, slowing productivity growth, and growing demand for agricultural commodities, it has adjusted its agricultural production system. Since the stable agricultural production system guarantees a sustainable food supply with safe and secure food products, it is important to explore the US agricultural sector's input demand and output supply systems. For a comprehensive analysis, this paper modeled the agricultural production systems 
using the differential approach to the theory of the multiproduct firm with a quasi-fixed input. From the differential approach, this paper examined the responses of input demand and output supply to changes in their respective prices and identified the relationships among primary inputs and outputs. Particularly, this paper contributed to the literature by identifying the relationships among labor, capital, and intermediate inputs and evaluating the relationships among livestock, farm-related, and crop outputs.

The results provide critical information about the agricultural production system. Regarding input demand, the inelastic input demand may raise a concern about the responsiveness of the agricultural sector to a rapid change in input prices. If a surge in input prices, for instance, raises production costs, it can induce a reduction in output supply or a rise in output prices. The higher the input prices are, the less the agricultural outputs may be supplied to the market, and the reduced supply, in turn, may contribute to a rise in the prices of agricultural outputs. The substitutable relationships may reduce the pressures on production costs in response to an increase in input prices, but its substitution effects on the cost reductions are relatively small due to the magnitudes of the estimates. In addition, land expansion is related to changes in input composition. As Hertel et al. [19] and Hertel [20] discussed the intensive and extensive margin, it is apparent that the agricultural sector's land expansion is accompanied by an increase in labor usage, but it reduces the intermediate inputs, such as energy and fertilizers.

Moreover, regarding output supply, the inelastic output supply shows that the agricultural sector is not likely to change its output supply despite its output prices. The results reveal that agricultural supply is limited to its production capacity, so price shocks can be transferred to producers if agricultural demand is more elastic than agricultural supply. However, the agricultural sector substitutes crop (livestock) for livestock (crop) when the relative price changes. Despite the small magnitudes of the estimates, the substitutability between livestock and crop supply implies that the agricultural sector reallocates resources to adjust output supply. Land expansion also leads to substitution between livestock and crop supply. Hertel's [20] discussion is extended to output supply because increasing the extensive margin can replace livestock supply with crop supply. The agricultural sector's decisions about the quasi-fixed input can be associated with changes in output composition in production as crop production requires more land areas, reducing land areas for livestock production.

As Shumway et al. [46] emphasized the importance of understanding input and output linkages when implementing policy measures, the findings suggest that agricultural policies should reflect the output relationships in supply to achieve stable agricultural and food prices because policy measures stimulating the crop (livestock) price can lead to a change in the supply of livestock (crop) due to the substitutable relationship between crop and livestock outputs in supply. If a policy measure stimulates crop prices, thereby increasing crop demand, the increased crop price may reduce livestock supply. Similarly, a policy measure raising livestock prices may cause a reduction in the supply of crops. For instance, ethanol expansion increased corn prices in the U.S. [11,21,23,47,48]. Accordingly, due to the increased corn prices, crop producers converted existing land for food and feed crops to land for corn $[22,25,36,43,45,49]$, and livestock producers put more feed costs for livestock production $[24,25]$. It seemed that the ethanol policy stimulated corn prices, and in turn, it induced the adjustment in livestock and crop supply. Even though the extent to which crop (livestock) prices affect the supply of livestock (crop) is relatively small, the output relationships in supply are important because formulating a policy that focuses only on one agricultural commodity may create unintended consequences in the supply of the other agricultural commodities. As the altered composition of output supply may eventually affect the prices of relevant agricultural and food commodities, policymakers are required to consider the output relationships in supply to ensure the stable supply of agricultural outputs. Admittedly, despite the implications of this study, the findings are based on the analysis of the aggregate data with broader categories of inputs and outputs. Promising research could result from a larger panel data with more detailed categories 
of inputs and outputs, which could capture more comprehensive information about the agricultural production system and provide policymakers with more valuable implications of input and output linkages.

\section{Conclusions}

The empirical analysis performed by the differential approach offered valuable estimates in terms of elasticities. The estimation results of the input demand system showed that livestock production required more intermediate inputs, but crop production depended on all the inputs, such as labor, capital, and intermediate inputs. In addition, the results revealed that the demand for inputs was very inelastic, indicating that the agricultural sector could have little flexibility in adjusting the input composition in response to changes in input prices. The substitutable relationship among labor, capital, and intermediate inputs showed a potential for alleviating the pressures on production costs in response to a surge in input prices. Regarding the quasi-fixed input, land expansion induced a change in the composition of labor and intermediate inputs, showing that the agricultural sector reduced the intensive margin increasing productivity when it pursued the extensive margin expanding land areas. Furthermore, the estimation results of the output supply system showed that agricultural supply was not very responsive to the respective price changes. There also existed statistical evidence that relative changes in the prices of livestock and crop outputs changed the output composition due to the substitutable relationship in supply. In addition, land expansion changed the output composition of crop and livestock in supply. The findings in this study are beneficial for policymakers because they show the linkages between inputs and outputs in the agricultural production system, suggesting that policy measures that focus only on a part of inputs or outputs consider their potential effects on other commodities' input demand and output supply due to their linkages.

Author Contributions: Conceptualization, D.H.S. and C.B.M.; methodology, D.H.S. and C.B.M.; software, D.H.S.; validation, C.B.M.; formal analysis, D.H.S.; writing-original draft preparation, D.H.S.; writing - review and editing, C.B.M. We have extended the paper presented at the 2014 annual meeting of the Agricultural and Applied Economics Association, and we have read and agreed to the published version of the manuscript.

Funding: This research was supported by a Korea University Grant (K1908061).

Institutional Review Board Statement: Not applicable.

Informed Consent Statement: Not applicable.

Data Availability Statement: Data sharing not applicable.

Acknowledgments: This research was supported by a Korea University Grant (K1908061).

Conflicts of Interest: The authors declare no conflict of interest.

\section{References}

1. Akter, S.; Basher, S.A. The impacts of food price and income shocks on household food security and economic well-being: Evidence from rural Bangladesh. Glob. Environ. Chang. 2014, 25, 150-162. [CrossRef]

2. Anríquez, G.; Daidone, S.; Mane, E. Rising food prices and undernourishment: A cross-country inquiry. Food Policy 2013, 38, 190-202. [CrossRef]

3. FAO. The State of Food Insecurity in the World 2008; Food and Agriculture Organization: Rome, Italy, 2009.

4. FAO. High Food Prices and the Food Crisis-Experiences and Lessons Learned; Food and Agriculture Organization: Rome, Italy, 2009.

5. Funk, C.C.; Brown, M.E. Declining global per capita agricultural production and warming oceans threaten food security. Food Secur. 2009, 1, 271-289. [CrossRef]

6. Grace, K.; Brown, M.E.; McNally, A. Examining the link between food prices and food insecurity: A multi-level analysis of maize price and birthweight in Kenya. Food Policy 2014, 46, 56-65. [CrossRef]

7. Ivanic, M.; Martin, W. Implications of higher global food prices for poverty in low-income countries. Agric. Econ. 2008, 39, 405-416. [CrossRef] 
8. Kalkuhl, M.; von Braun, J.; Torero, M. Food Price Volatility and Its Implications for Food Security and Policy; Springer: New York, NY, USA, 2016. [CrossRef]

9. Rosegrant, M.W.; Cline, S.A. Global food security: Challenges and policies. Science 2003, 302, 1917-1919. [CrossRef]

10. Swinnen, J.; Squicciarini, P. Mixed Messages on Prices and Food Security. Sci. 2012, 335, 405-406. [CrossRef]

11. Abbott, P.C.; Hurt, C.; Tyner, W.E. What's driving food prices in 2011? Issue Report 2011. [CrossRef]

12. Ball, E.; Schimmelpfennig, D.; Wang, S.L. Is U.S. Agricultural Productivity Growth Slowing? Appl. Econ. Perspect. Policy 2013, 35, 435-450. [CrossRef]

13. McCalla, A. World Food Prices: Causes and Consequences. Can. J. Agric. Econ. 2009, 57, 23-34. [CrossRef]

14. Mitchell, D.O. A Note on Rising Food Prices. In Development Prospects Group; World Bank: Washington, DC, USA, 2008. [CrossRef]

15. Mittal, A. The 2008 Food Price Crisis: Rethinking Food Security Policies. In G-24 Discussion Papers 56; United Nations Conference on Trade and Development: Geneva, Switzerland, 2009.

16. Wang, S.L.; Heisey, P.; Schimmelpfennig, D.; Ball, V.E. Agricultural productivity growth in the United States: Measurement, trends, and drivers. Econ. Res. Serv. 2015. [CrossRef]

17. Ruttan, V.W. Productivity Growth in World Agriculture: Sources and Constraints. J. Econ. Perspect. 2002, 16, 161-184. [CrossRef]

18. Suh, D.H. Declining Energy Intensity in the U.S. Agricultural Sector: Implications for Factor Substitution and Technological Change. Sustainability 2015, 7, 13192-13205. [CrossRef]

19. Hertel, T.W.; Stiegert, K.; Vroomen, H. Nitrogen-Land Substitution in Corn Production: A Reconciliation of Aggregate and Firm-Level Evidence. Am. J. Agric. Econ. 1996, 78, 30-40. [CrossRef]

20. Hertel, T.W. The Global Supply and Demand for Agricultural Land in 2050: A Perfect Storm in the Making? Am. J. Agric. Econ. 2011, 93, 259-275. [CrossRef]

21. Pimental, D. Ethanol fuels: Energy security, economics, and the environment. Nat. Resour. Res. 2003, 12, 127-134. [CrossRef]

22. Suh, D.H.; Moss, C.B. Examining crop price effects on production decision and resource allocation: An ex-ante approach. Appl. Econ. 2017, 50, 2909-2919. [CrossRef]

23. Tokgoz, S.; Elobeid, A.; Fabiosa, J.; Hayes, D.J.; Babcock, B.A.; Yu, T.H.; Dong, F.; Hart, C.E. Bottlenecks, drought, and oil price spikes: Impact on US ethanol and agricultural sectors. Rev. Agric. Econ. 2008, 30, 604-622. [CrossRef]

24. Suh, D.H.; Moss, C.B. Decompositions of corn price effects: Implications for feed grain demand and livestock supply. Agric. Econ. 2017, 48, 491-500. [CrossRef]

25. Miljkovic, D.; Shaik, S.; Braun, D. Impact of biofuel policies on livestock production in the United States. J. Policy Model. 2012, 34, 817-831. [CrossRef]

26. Banasik, A.; Kanellopoulos, A.; Claassen, G.; Bloemhof-Ruwaard, J.M.; van der Vorst, J.G. Closing loops in agricultural supply chains using multi-objective optimization: A case study of an industrial mushroom supply chain. Int. J. Prod. Econ. 2017, 183, 409-420. [CrossRef]

27. Ge, H.; Gray, R.; Nolan, J. Agricultural supply chain optimization and complexity: A comparison of analytic vs simulated solutions and policies. Int. J. Prod. Econ. 2015, 159, 208-220. [CrossRef]

28. Jana, R.K.; Sharma, D.K.; Chakraborty, B. A hybrid probabilistic fuzzy goal programming approach for agricultural decisionmaking. Int. J. Prod. Econ. 2016, 173, 134-141. [CrossRef]

29. Palominos, P.I.; Quezada, L.E.; Moncada, G. Modeling the response capability of a production system. Int. J. Prod. Econ. 2009, 122, 458-468. [CrossRef]

30. Armstrong, J.S. Standards and Practices for Forecasting. Principles of Forecasting; Springer: Boston, MA, USA, 2001 ; pp. 679-732.

31. Clements, K.W. An aggregative multiproduct supply model. Eur. Econ. Rev. 1980, 13, 239-245. [CrossRef]

32. Clements, K.W.; Izan, H. More on an aggregative multiproduct supply model. Eur. Econ. Rev. 1982, 17, 271-276. [CrossRef]

33. Clements, K.W.; Theil, H. A simple method of estimating price elasticities in international trade. Econ. Lett. 1978, 1, 133-137. [CrossRef]

34. Fousekis, P.; Pantzios, C. A Family of Differential Input Demand Systems with Application to Greek Agriculture. J. Agric. Econ. 2008, 50, 549-563. [CrossRef]

35. Laitinen, K. A Theory of the Multiproduct Firm; North Holland Publishing: Amsterdam, The Netherlands, 1980.

36. Laitinen, K.; Theil, H. Supply and demand of the multiproduct firm. Eur. Econ. Rev. 1978, 11, 107-154. [CrossRef]

37. Livanis, G.; Moss, C.B. Quasi-fixity and multiproduct firms. Econ. Lett. 2006, 93, 228-234. [CrossRef]

38. Moss, C.B.; Livanis, G.T.; Schmitz, A. The Effect of Increased Energy Prices on Agriculture: A Differential Supply Approach. J. Agric. Appl. Econ. 2010, 42, 711-718. [CrossRef]

39. Rossi, N. The Estimation of Product Supply and Input Demand by the Differential Approach. Am. J. Agric. Econ. 1984, 66, 368-375. [CrossRef]

40. Theil, H. The System-Wide Approach to Microeconomics; The University of Chicago Press: Chicago, IL, USA, 1980.

41. Cameron, A.; Trivedi, P. Microeconometrics: Methods and Applications; Cambridge University Press: New York, NY, USA, 2005.

42. Terrell, D. Incorporating monotonicity and concavity conditions in flexible functional forms. J. Appl. Econ. 1996, 11, 179-194. [CrossRef]

43. Wolff, H.; Heckelei, T.; Mittelhammer, R.C. Imposing curvature and monotonicity on flexible functional forms: An efficient regional approach. Comput. Econ. 2010, 36, 309-339. [CrossRef]

44. Chambers, R.G. Applied Production Analysis: A Dual Approach; Cambridge University Press: Cambridge, UK, 1988. 
45. Piroli, G.; Ciaian, P.; Kancs, D. Land use change impacts of biofuels: Near-VAR evidence from the U.S. Ecol. Econ. 2012, 84, 98-109. [CrossRef]

46. Shumway, C.R.; Saez, R.R.; Gottret, P.E. Multiproduct Supply and Input Demand in U.S. Agriculture. Am. J. Agric. Econ. 1988, 70, 330-337. [CrossRef]

47. Elobeid, A.; Hart, C. Ethanol Expansion in the Food versus Fuel Debate: How Will Developing Countries Fare? J. Agric. Food Ind. Organ. 2007, 5. [CrossRef]

48. Chen, X.; Khanna, M. Food vs. Fuel: The Effect of Biofuel Policies. Am. J. Agric. Econ. 2012, 95, 289-295. [CrossRef]

49. Keeney, R.; Hertel, T.W. The indirect land use impacts of U.S. biofuel policies: The importance of acreage, yield, and bilateral trade responses. Am. J. Agric. Econ. 2011, 91, 895-909. [CrossRef] 